\title{
Benefits of Amplification in Cases of Subjective Tinnitus
}

\author{
Max Stanley Chartrand* \\ Director of Research/DigiCare Behavioral Research, USA
}

Submission: April 09, 2018; Published: April 26, 2018

*Corresponding author: Max Stanley Chartrand, Director of Research/DigiCare Behavioral Research, USA, Tel: (520)509-6380;

Email: chartrandmax@aol.com

\section{Opinion}

Tinnitus is described as a "noise perceived in the absence of a known external sound source." The number of Americans experiencing tinnitus is upwards of 50 million adults. Of those, approximately 20 million Americans say their lives are significant disrupted by the malady, while about 2 million report debilitation from incessant and unrelenting tinnitus (American Tinnitus Association [1]; NIDCD, 2016). Those suffering from

bothersome levels of tinnitus describe their tinnitus using imagery and analogous terms, such as a "high pitch ring," "buzzing," "crickets," "locusts," "roaring," and "frying" (Foreman [2]; Chartrand, 2007). From large-scale, longitudinal study back in the 1980s, the author and his associates found the proportion of tinnitus descriptors from a sample of 100 adults from that study as shown in Table 1.

Table 1: Subjective descriptions of tinnitus in a population of hearing aid users.

\begin{tabular}{|c|c|c|c|c|}
\hline $\begin{array}{c}\text { \% Focus } \\
\text { Group }\end{array}$ & $\begin{array}{c}\text { Verbal } \\
\text { Descriptions }\end{array}$ & $\begin{array}{c}\text { Audiometer } \\
\text { Comparison }\end{array}$ & Frequency Ranges & Suspected Site/lesion \\
\hline 63 & "Ringing" & Pure-tones & $1.5 \mathrm{~K}-8 \mathrm{KHz}$ & Cochlea/OHC \\
\hline 27 & "Buzzing" & NB Masking & $.5 \mathrm{~K}-3 \mathrm{KHz}$ & Cochlea/OHC \\
\hline 11 & "Pulsating" & WB Masking & Varies & ME/Vascular \\
\hline 07 & "Crickets" & NB Masking & $1 \mathrm{~K}-4 \mathrm{KHz}$ & Cochlea/ME/Vas \\
\hline 07 & Multi-Band & WB Masking & Varies & ME $/$ Vas/Cochlea \\
\hline
\end{tabular}

Subsequent studies concurred with the proportion and types of descriptors, showing widespread generalizability of the data from the early study. The proportions show $63 \%$ report "ringing" (generally in the $3-4 \mathrm{~Hz}$ range), 27\% reported "buzzing", 11\% reported a "pulsation" which could overlap with other descriptors, while $7 \%$ reported hearing "crickets or locusts" and 7\% reporting "multiple sounds". (Chartrand, 2007; Chartrand, [3]; Rabinowitz, [4]). Furthermore, of these, the cases identified as potential medically treatable were found to suffer from otologic disorders and lesions, such as otosclerosis, vascular constrictions, impacted cerumen, keratosis obturans, glomus tumor, allergy, infection, Meniere's, endolymphatic hydrops, and conductive hearing loss, in general (Parker [5]; Yoo et al. [6]; Hoover, Marchiando, Per-Lee, and Jackson).

Almost all the losses involving the descriptors "ringing"," crickets," or "locusts" exhibited precipitous high frequency sensorineural losses, where lows were mild or normal, while those with "buzzing", "roaring", or lower frequency tinnitus exhibited audiograms with low frequency, reverse slope, or mildly sloping mixed losses, with at least some conductive components. of course, not all individuals with sensorineural high frequency hearing loss have tinnitus. However, it is generally accepted that at least $80 \%$ of those with high frequency hearing loss that can also benefit from wearing properly fitted hearing aid also suffer with tinnitus (Vernon [7], Chartrand). Consequently, it has been suggested by many prominent researchers and practitioners that hearing aids offer the greatest benefits for the largest number of tinnitus and hearing loss sufferers. The four prominent hearing aid benefits for tinnitus management have been variously described as follows: (Anonymous [8]; Chartrand [9]; Friedenberg, Foreman [2]; Nodar [10]; Chartrand [3,10,11]; Vernon [12]; Hazell, Vernon [13-16]):

a) Residual Inhibition (RI) is the temporary suppression of tinnitus after cessation of an amplified stimulus. In other words, the patient reports relief from tinnitus, even after the hearing aid (or other amplification system) is removed. In practical terms, hearing aid users who suffer also with subjective forms of tinnitus report a lessening of the tinnitus loudness in some cases, complete cessation of the tinnitus when they wear their hearing aids for a period of time. 
b) Environmental Masking (EM) effectively masks the tinnitus noise with amplified sounds from the auditory environment. This is a simple protocol in which the sounds of the local environment (speech, background, etc) are amplified, and they "cover up" or "mask" the tinnitus, while the amplification is available. A corresponding goal of TRT would be to provide "low-level masking", which can be provided by the environment through appropriately fitted amplification.

c) Auditory Reattention (AR) through effective hearing "correction," AR provides the patient with signals other than tinnitus to listen to. In TRT, the goal of this benefit is to provide naturally occurring sounds rather than artificially contrived sounds of a masker. This allows the user to attend to true and existing signals while "habituating" (i.e., accepting) to the tinnitus noise. While this is a psychological construct, it does represent a real and noted benefit of wearing hearing aids for hearing loss.

d) Stress Relief (SR) results from realizing any or all of the above-described benefits. Under this benefit, residual inhibition, environmental masking, and/or auditory re attention serve to lessen the bothersome and aversive aspects of tinnitus. In combination, the benefits become additive.

In conclusion, the single most beneficial approach to tinnitus management and hearing loss appears to lie in the appropriate fitting of hearing aids. Bringing in the lost hearing (through amplification) calls off the proverbial "search party" or "phantom hearing" process and thereby reduces the tinnitus complaint through residual inhibition. Likewise, by bringing into sharper focus the background sounds of the environment hearing aid users are also enjoying a palpable level of "masking" of the tinnitus complaint, while their attention is redirected to the actual signals of the listening environment through "reattention". These benefits have been described in the literature in detail for at least the past three decades yet seem to elude the attention of those suffering from tinnitus and those taking care of them. It is hoped that this paper brings those benefits to light to more professionals, and, by extension, to those who suffer from constant and unrelenting tinnitus.

\section{References}

1. American Tinnitus Association (2018) Home page of the American Tinnitus Association.

2. Foreman J (2004) Q: How can I stop my ears from ringing? ST Cambridge. Boston Globe p. C-2.

3. Chartrand MS (1989) Tinnitus and Amplification. Audecibel p. 18-21.

4. Rabinowitz PM (2000) Noise-Induced Hearing Loss. American Academy of Family Physicians.

5. Parker JF (2004) Post initial neurofeedback experience of functional adults: A qualitative study. Argosy University-Sarasota, Source: DAI-B 65/04, p. 1772.

6. Yoo TJ, Shulman A, Brummet RE, Griest SE, Mulkey M, et al. (1991) Specific Etiologies of Tinnitus. In Tinnitus: Diagnosis \& Treatment, Shulman, Lea, and Febriger (eds.), pp. 342-415.

7. Chartrand MS (1996) Psycho-Social Principles of Hearing Impairment. In Hearing Science \& Fitting Practices, $2^{\text {nd }}$ edn, Sandlin, Instrument RE pp. 741-792.

8. Anonymous (2017) The Truth About What Hearing Aids can do for Tinnitus.

9. Chartrand MS (2005) Tinnitus Loudness Perception in Precipitous HL Losses.

10. Chartrand MS (2003) Tinnitus Retraining Therapy and Concepts of Amplification. The Hearing Professional p. 7-10.

11. Chartrand MS (1993) Tinnitus Management in the Dispensing Practice. Audecibel p. 7-10.

12. Vernon J (1988) Current use of masking for the relief of tinnitus. Tinnitus, Pathology, and Management. Kitahara J (Eds.), pp. 96-106.

13. Vernon J (1964) Tinnitus "loudness" as indicated by masking levels with environmental sounds. J Laryngo Otol Suppl 9: 59-62.

14. Andersson G, Eericksson J, Lundh L, Lyttkens L (2000) Tinnitus and cognitive interference: A stroop paradigm study. J Speech Lang Hear Res 43(5): 1168-1172.

15. Chartrand MS (1994) Inferential Correlates Derived from a Tinnitus and Hearing Impairment Survey Among Hearing Health Professionals. Rye CO: Aural Rehab Concepts p. 24.

16. Nodar R (2002) Techniques for Tinnitus Management. The Hearing Professional p. 5-8.

\section{Your next submission with Juniper Publishers} will reach you the below assets

- Quality Editorial service

- Swift Peer Review

- Reprints availability

- E-prints Service

- Manuscript Podcast for convenient understanding

- Global attainment for your research

- Manuscript accessibility in different formats

( Pdf, E-pub, Full Text, Audio)

- Unceasing customer service

Track the below URL for one-step submission https://juniperpublishers.com/online-submission.php 